EXTENDED REPORT

\title{
Tumour necrosis factor $\alpha$ independent disease mechanisms in rheumatoid arthritis: a histopathological study on the effect of infliximab on rheumatoid nodules
}

\author{
D Baeten, F De Keyser, E M Veys, Y Theate, F A Houssiau, P Durez
}

Ann Rheum Dis 2004;63:489-493. doi: 10.1136/ard.2003.012302

See end of article for authors' affiliations

Correspondence to: Dr D Baeten, Department of Rheumatology, OK12IB, Ghent University Hospital, De Pintelaan 185, 9000 Gent, Belgium; dominique. baeten@ugent.be

Accepted 29 July 2003
Background: It has been suggested that the immunopathology of rheumatoid nodules parallels that of inflamed synovium in rheumatoid arthritis (RA).

Objective: To analyse the effect of infliximab on the immunopathology of rheumatoid nodules in order to provide new insights into the relationship between synovial inflammation and rheumatoid nodules.

Materials and methods: Nodules were present at baseline in six patients with RA and after infliximab treatment in five patients, including paired nodules before and after treatment in three patients. In one patient, the nodule appeared during treatment. Paraffin sections were used for histological analysis. Frozen sections were stained by immunohistochemistry for cellular markers (CD3, CD4, CD8, CD16, CD20, CD68), blood vessels (CD146, vWF, av 33 ), and adhesion molecules (E-selectin, VCAM-1, ICAM1).

Results: No manifest immunopathological differences were found between the nodules before and after infliximab treatment. All nodules depicted the classical structure with a central necrotic zone, surrounding the palisade layer, and an outer connective tissue zone. Immunohistochemistry showed the presence of CD68+ and CD16+ macrophages in the palisade and the connective tissue zone, as well as a small number of CD3+, CD4+ T lymphocytes in the perivascular areas. Small vessels were seen in the connective tissue and were sometimes positive for the neovascularisation marker av $\beta 3$. They expressed no VCAM-1, E-selectin weakly, but ICAM-1 strongly. ICAM-1 was also strongly expressed on palisade cells.

Conclusions: Despite an improvement of articular symptoms, infliximab treatment had no distinct effect on the histopathology of rheumatoid nodules, suggesting that different pathogenetic mechanisms mediate the two disease manifestations in RA.
$\mathrm{R}$ heumatoid nodules are the most characteristic extraarticular manifestation of rheumatoid arthritis (RA), occurring in about $25 \%$ of rheumatoid factor (RF) positive patients with RA. ${ }^{1}$ They are typically located in subcutaneous tissues overlying bone or in other places of mechanical stress (lungs, heart valves). Histologically, three characteristic zones can be recognised in the rheumatoid nodule. The inner zone of central necrosis contains fibrinoid deposits and necrotic material, but no living cells. A palisade zone surrounds the central necrosis and is essentially composed of radially arranged macrophages, but also contains some fibroblasts. ${ }^{2}$ Finally, the outer connective tissue zone surrounds the palisade zone and is composed of connective tissue with macrophages and fibroblasts, a large number of small vessels, and a moderate number of infiltrating (mostly perivascular) lymphocytes. Clinically, there is an intriguing discrepancy between active joint inflammation and the extensive presence of nodules, not only in the natural course of the disease but also in the function of disease modifying antirheumatic disease treatment, as illustrated by the worsening nodulosis in patients with RA treated with methotrexate (MTX). ${ }^{3}$ Because this observation suggests that joint inflammation and nodulosis are not driven by the same pathogenetic mechanisms, it would be of interest to analyse the effect of the newer, very potent biological drugs for RA, on rheumatoid nodules. Despite the numerous studies and widespread use of tumour necrosis factor $\alpha(\mathrm{TNF} \alpha)$ blockers such as infliximab and etanercept, only one systematic prospective clinical study has indicated that etanercept had neither an efficacious nor a deleterious effect on nodules. ${ }^{4}$ On the other hand, four cases were described in which patients with RA developed nodules during etanercept treatment, even when they had clear articular and inflammatory improvement. ${ }^{56}$ There are at present no studies comparing the histology of rheumatoid nodules before and after TNF $\alpha$ blockade or any data on the effect of infliximab on nodules. The present study analysed histologically and immunopathologically the effect of infliximab on rheumatoid nodules in order to evaluate the response and the pathogenic processes relevant to this systemic feature of RA.

\section{PATIENTS AND METHODS \\ Patients}

Eight patients fulfilling the American College of Rheumatology (ACR) criteria for RA and having nodules of the juxta-articular area were included in this study after informed consent was obtained. Five of these patients had erosive, refractory disease and received infliximab $(3 \mathrm{mg} / \mathrm{kg})$ at weeks $0,2,6$, and subsequently every 8 weeks in combination with MTX (at least $15 \mathrm{mg} /$ week) and low dose prednisone $(<10 \mathrm{mg} /$ day $)$. Painful or disturbing rheumatoid nodules were removed from the olecranon area, the feet, or the fingers under local anaesthesia. Table 1 shows that the study analysed nodules of six patients who had not received infliximab and nodules of five patients after infliximab

\footnotetext{
Abbreviations: ACR, American College of Rheumatology; MTX, methotrexate; RA, rheumatoid arthritis; RF, rheumatoid factor; TNF $\alpha$, tumour necrosis factor $\alpha$; vWF, von Willebrand factor
} 

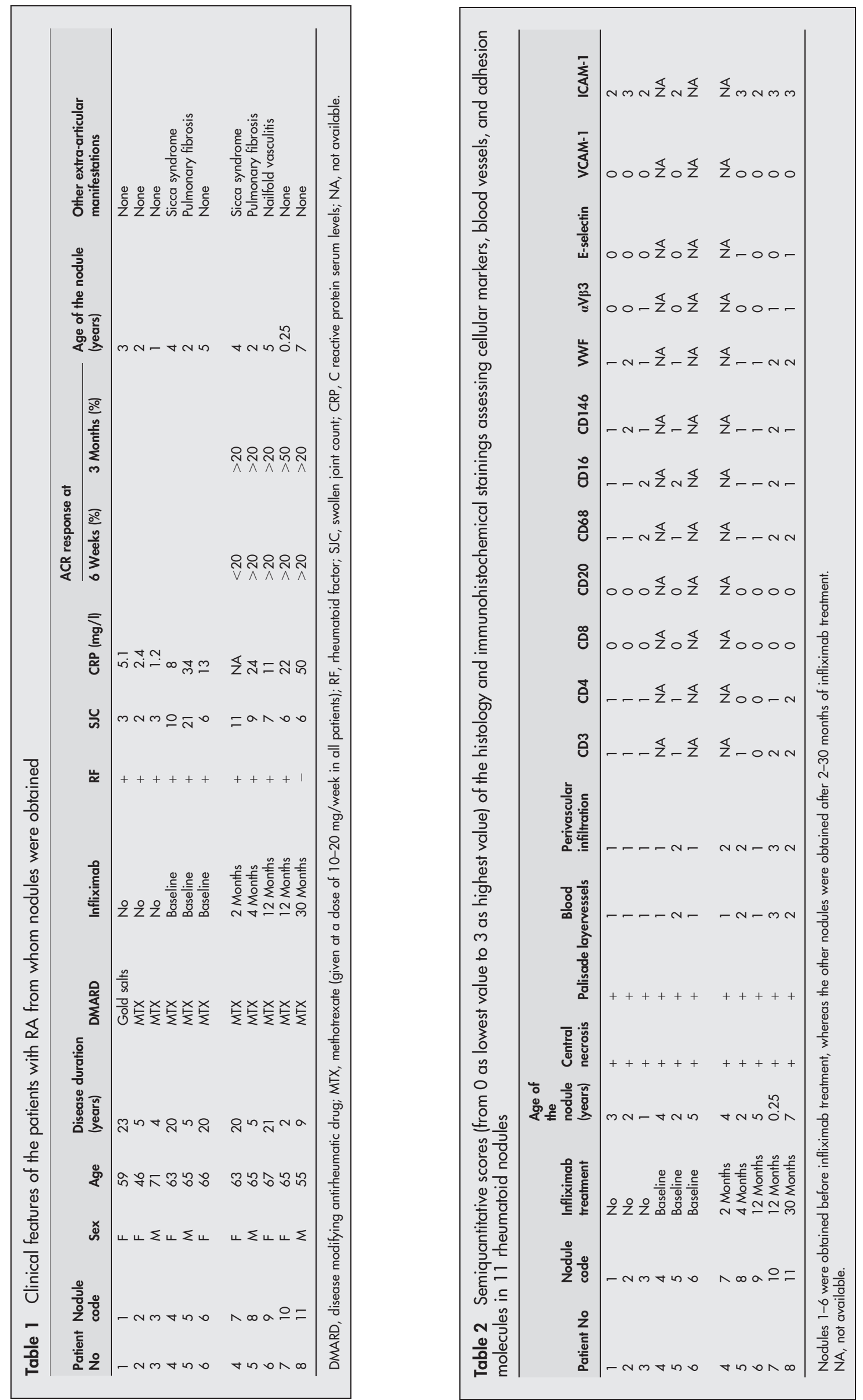

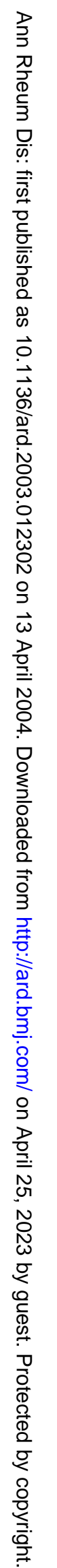



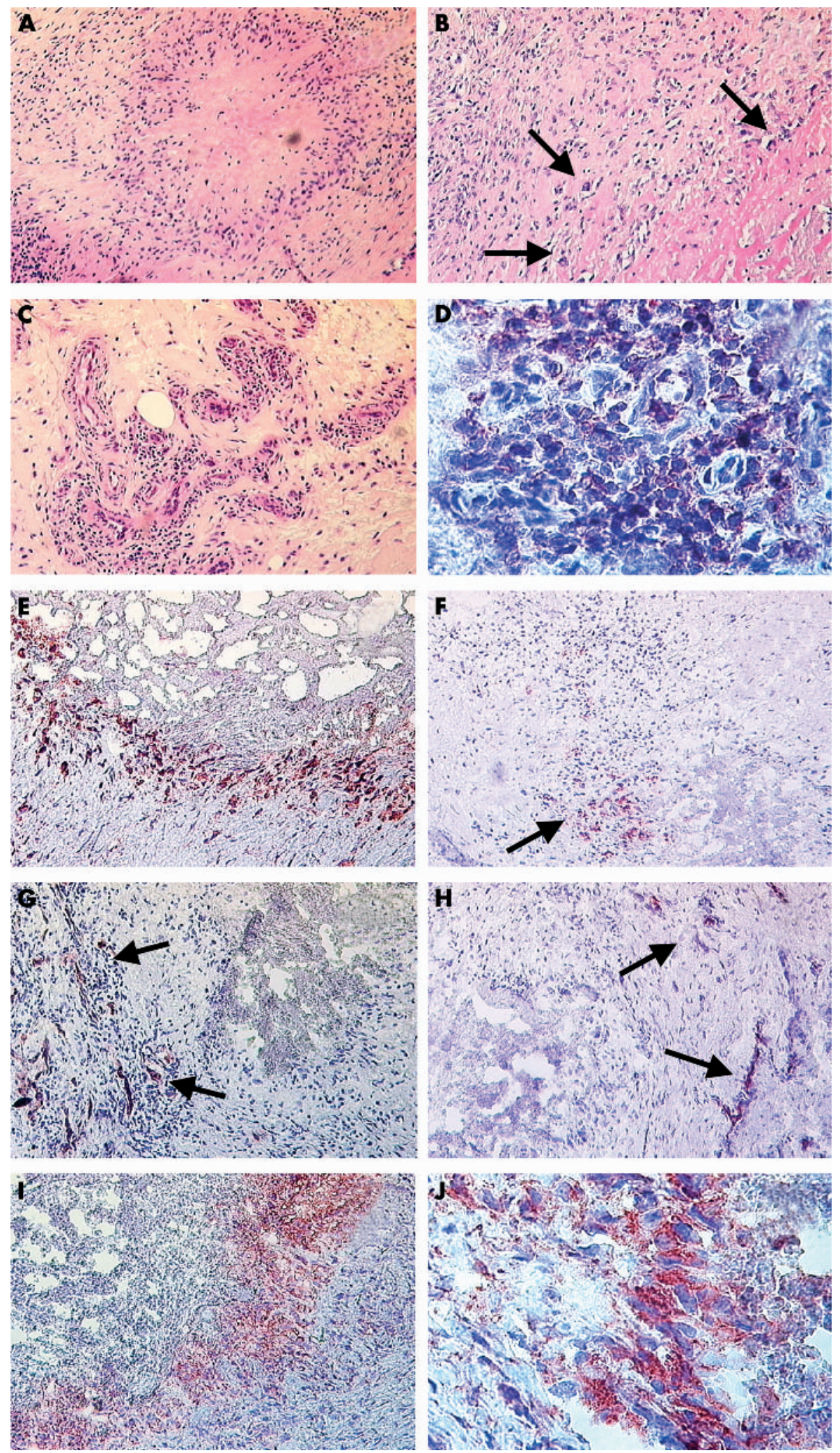

Figure 1 Immunohistochemical analysis of the effect of infliximab on cellular markers, blood vessels, and adhesion molecules in rheumatoid nodules. The nodules were obtained after 6-24 months of infliximab treatment. (A) Central necrotic zone with palisade layer (original magnification $\times 160)$; (B) palisade layer with radially orientated mononuclear cells and occasional multinucleated giant cells (original magnification $\times 160$ ); (C) outer connective tissue zone with small blood vessels and perivascular infiltration with lymphocyte-like mononuclear cells (original magnification $\times 160) ;(D)$ anti-CD3 staining (original magnification $\times 320$ ); $(E)$ anti-CD68 staining (original magnification $\times 160)$; $(F)$ anti-CD16 staining (original magnification $\times 160)$; (G) anti-vWF staining (original magnification $\times 160$ ); $(\mathrm{H})$ anti- $\alpha \mathrm{V} \beta 3$ staining (original magnification $\times 160$ ); (I) anti-ICAM-1 staining (original magnification $\times 160)$; $(\mathrm{J})$ anti-ICAM-1 staining (original magnification $\times 320)$. 
treatment, with three paired observations before and after infliximab treatment. Nodules were obtained from three patients independently of infliximab treatment, from three patients both at baseline and after 2-12 months of infliximab, and from two patients after respectively 12 and 30 months of infliximab.

\section{Histopathological analysis}

The 11 nodules were mounted in paraffin and sections were stained with haematoxylin and eosin for histological analysis by two "blinded" observers (DB and YT). In eight nodules (four baseline and four after infliximab treatment (see table 2 for details)), tissue was also available for immunohistochemistry. The nodules were mounted in freezing medium and $5 \mu \mathrm{m}$ sections were cut. The frozen sections were stained by a peroxidase technique, as extensively reported previously. ${ }^{7}$ The sections were stained with mouse monoclonal antibodies directed against following cell surface markers and adhesion molecules: CD3 ( $\mathrm{T}$ cells, clone UCHTl; Dako, Glostrup, Denmark), CD4 (T helper cells, clone MT310; Dako), CD8 ( $\mathrm{T}$ suppressor/cytotoxic cells, clone DK25; Dako), CD16 (Fc $\gamma$ III receptor, expressed on a subset of neutrophils and monocytes, clone 3G8; Immunotech, Marseille, France), CD20 (B cells, clone L26; Dako), CD54 (ICAM-1, clone 6.5B5; Dako), CD62E (E-selectin, clone 1.2B6; Dako), CD68 (macrophages, clone PG-Ml; Dako), CDl06 (VCAM-1, clone 1.4C3; Dako), CDl46 (endothelial cells, clone PlH12; Chemicon, Temecula, USA), von Willebrand factor (vWF; endothelial cells, clone F8/86; Dako), and the integrin $\alpha \mathrm{V} \beta 3$ (a marker of neovascularisation, clone 23C6; Pharmingen, San Diego, USA). Parallel sections were incubated with irrelevant isotype and concentration matched monoclonal antibodies as negative control. Stained sections were coded and scored on a semiquantitative four point scale. ${ }^{78}$

\section{RESULTS}

Clinical analysis of the five infliximab treated patients As shown in (table 1 , four of the five infliximab treated patients met the ACR 20\% improvement criteria already at 6 weeks of infliximab treatment and all five met the criteria at 3 months (one patient met the ACR 50\% improvement criteria). Therefore these patients were classified as responders to infliximab, although only three of the five patients (Nos 5, 7, and 8) had a clear decrease in swollen joint count between baseline and the time of nodule resection; in the two other patients (Nos 4 and 6) with a more longstanding RA, the number of swollen joints remained stable. Similarly, C reactive protein serum levels were decreased in only three patients, but this might be a biased reflection of clinical response because they were assessed 8 weeks after the last infusion of infliximab. Interestingly, in four of the five patients, prednisone could be tapered while MTX remained stable.

The clinical nodulosis was stable in three of the five patients (Nos 4, 5, and 8), despite the clear improvement of the swollen joint count in two of them. New nodules as well as mild nailfold vasculitis appeared during infliximab treatment in one patient (No 6). The fifth patient (No 7), who was treated with a high dose of MTX (20 mg/week), had no rheumatoid nodules at baseline but developed a unique nodule of the olecranon region after 9 months of infliximab treatment, whereas there was a clear decrease of both the swollen joint count and the $\mathrm{C}$ reactive protein.

\section{Histological analysis of the nodules}

The global histological structure of the 11 nodules was similar, independently of the time of sampling and the fact that they developed before or during infliximab treatment (table 2). All nodules had clear regions of central necrosis, surrounded by a palisade layer of radially orientated mononuclear cells and, occasionally, multinucleated giant cells (figs $1 \mathrm{~A}$ and $\mathrm{B}$ ). These characteristic structures were embedded in loose connective tissue containing a small number of mononuclear cells. In some regions, mostly located at the periphery of the nodules, a moderate number of small blood vessels were observed; some of these vessels were surrounded by perivascular infiltrates of lymphocytelike mononuclear cells (fig $1 \mathrm{C}$ ). There were no manifest histological differences between the nodules formed before and after infliximab treatment.

\section{Immunohistochemical analysis}

Four baseline and four nodules after infliximab treatment were assessed by immunohistochemistry. Globally, all eight nodules had a similar staining pattern for the different cellular markers and adhesion molecules (table 2). The cellular infiltration was characterised by a small to moderate number of $\mathrm{CD} 3+\mathrm{T}$ lymphocytes, mostly localised in the vicinity of small blood vessels in the surrounding connective tissue zone (fig 1D). Almost all T lymphocytes were CD4+, whereas no CD8+ cells were detected. The number of CD20+ B cells was extremely low (score zero for all nodules). As for macrophages, CD68+ macrophages were found in the palisade layer as well as in the surrounding connective tissue zone (fig lE). Although less numerous than the CD68+ macrophages, CDl6+ mononuclear cells were found throughout the nodules but especially in the vicinity of the palisade layer (fig $1 \mathrm{~F}$ ). Small vessels were found exclusively in the periphery of the surrounding connective tissue zone. They were consistently positive for the endothelial cell markers vWF and CDI46 (fig lG). In two nodules obtained after respectively 1 and 2 years of infliximab treatment, some of these small vessels expressed the $\alpha \mathrm{V} \beta 3$ integrin, pointing to a certain degree of neovascularisation (fig $1 \mathrm{H}$ ). As to the adhesion molecules, VCAM-1 expression was absent from blood vessels and palisade layer. E-selectin expression was negative in the nodules before infliximab treatment and in two nodules after infliximab treatment; in the two other nodules, a faint expression was noticed on the endothelium. In contrast, ICAM-1 was strongly expressed in all samples both on endothelium and on cells of the palisade layer (figs II and $\mathrm{J}$ ).

\section{DISCUSSION}

Three studies have previously compared the immunopathology of the rheumatoid nodule and the synovial membrane in $\mathrm{RA}$ in order to analyse putative common pathogenic mechanisms. ${ }^{289}$ They indicated a number of striking similarities between synovium and nodules: similar expression of adhesion molecules (except for E-selectin expression, which was higher in nodules), palisade formation mimicking the proliferation of the synovial lining, predominant infiltration with $\mathrm{CD} 68+$ macrophages which produce proinflammatory cytokines such as TNF $\alpha$ and interleukin $1 \beta$, and perivascular $\mathrm{CD} 3+\mathrm{T}$ cells. These findings suggested that inflammation mediated by macrophages, amplified by adhesion molecule expression and continuous influx of additional inflammatory cells, might be similar in the synovium and nodule. However, there were also important histopathological differences between both disease manifestations: the absence of necrosis in the synovial membrane, the absence of B cells, plasma cells, and lymphoid follicles in the nodules, and the differential expression of VCAM-1. This study confirms the global baseline histopathological structure described in the previously mentioned reports, but challenges the concept of similar disease mechanisms in inflamed synovium and rheumatoid nodules by indicating no detectable effect of TNF $\alpha$ blockade by infliximab on the clinical presentation and 
the histopathology of the rheumatoid nodules. This is to our knowledge the first systematic comparison of rheumatoid nodules before and after treatment with infliximab, which extends histopathologically previous case reports with another TNF $\alpha$ blocker, etanercept. ${ }^{67}$ The absence of a detectable histopathological effect of infliximab on the rheumatoid nodule contrasts with the improvement of peripheral joint and global inflammation in these patients (all patients met the ACR 20\% improvement criteria at 3 months despite tapering prednisone in four of the five patients and stable MTX in all patients). Moreover, whereas the limited number of observations (due to the ethical and clinical difficulty of performing sequential surgical interventions for a rather mild disease manifestation), the semiquantitative approach (which might be relatively insensitive to small changes), and the variable timing of biopsy sampling (between 1 and 7 weeks after infliximab infusion) suggests that some caution is needed in the interpretation of the present results, the absence of any detectable effect on rheumatoid nodules remains in sharp contrast with the previously documented histopathological effect on autoimmune synovitis observations using an identical approach. ${ }^{7}$

Different explanations can be envisaged for the absence of a detectable effect of infliximab on rheumatoid nodules. Firstly, it may be that the drug cannot effectively penetrate the nodules owing to the specific granuloma-like architecture. Although this hypothesis cannot be formally excluded, it is in contradiction with the clear presence of blood vessels in the outer connective tissue zone and with the effect of infliximab on other granuloma-like structures such as in tuberculosis. ${ }^{11}$ Secondly, longstanding rheumatoid nodules may have to be considered as residual lesions that become insensitive to anti-inflammatory treatment once the active inflammatory process has terminated. This theory, however, cannot explain the appearance of new nodules in two of the patients or the presence of nodules after infliximab treatment of features of active inflammation such as $\alpha \mathrm{V} \beta 3$ positive vessels, ICAM-1, and E-selectin expression, and perivascular lymphocyte infiltration. It is interesting to note that inhibition of vascular activation by $\mathrm{TNF} \alpha$ and subsequent infiltration with inflammatory cells was proposed as one of the major modes of action of infliximab in peripheral joint inflammation..$^{70}$ The third and most likely explanation is that, although $\mathrm{TNF} \alpha$ may have some role in nodulosis, the pivotal mechanisms of these lesions are largely TNF $\alpha$ independent. Such alternative mechanisms might include adenosine release by monocytes induced by $\mathrm{MTX}^{12}$ and/or the stimulation of specific macrophage subsets expressing the FcyIIIa receptor $(\mathrm{CDl})$ by small immune complexes as proposed by Edwards and coworkers. ${ }^{13}$ Self associated dimeric complexes of IgG RF could evade clearance by complement receptors and diffuse into the extravascular space, especially at sites of mechanical stress and repetitive microtrauma. When binding to macrophages through the FcyIIIa receptor, this could lead to stimulation of these cells, production and release of cytokines and growth factors such as transforming growth factor $\beta$, and, ultimately, nodule formation. This hypothesis is supported by the fact that nodules are almost exclusively found in RF positive patients, that Fc $\gamma$ IIIa positive macrophages are preferentially found at sites of biomechanical stress such as the dermis on extensor sites, which are the typical localisation for rheumatoid nodules, ${ }^{14}$ and that Fc $\gamma$ IIIIa polymorphism is associated with nodular disease. ${ }^{15}$ Accordingly, the present study indicates that a subset of the CD68+ macrophages, present in nodules both before and after infliximab treatment, expresses the FcrIIIa receptor, especially in the palisade layer. These observations warrant further research on the role of small immune complexes and their receptors in the pathogenesis of rheumatoid nodules as well as other extra-articular manifestations in RA.

In conclusion, this study demonstrated no distinct effect of infliximab treatment on the clinical and histopathological presentation of rheumatoid nodules, despite an improvement of joint inflammation. These data support the concept that synovial inflammation and nodule formation in RA are, at least partially, mediated by different mechanisms. Although immune complex mediated activation of specific macrophage subsets is likely to play a part at both disease sites, we propose that this results in TNF $\alpha$ dependent mechanisms of inflammation in synovitis but leads to a largely $\mathrm{TNF} \alpha$ independent proliferative connective tissue lesion in the nodule.

\section{Authors' affiliations}

D Baeten, F De Keyser, E M Veys, Department of Rheumatology, Ghent University Hospital, Belgium

Y Theate, Department of Pathology, Cliniques Universitaires St Luc, Université Catholique de Louvain, Brussels, Belgium

F A Houssiau, P Durez, Department of Rheumatology, Cliniques Universitaires St Luc, Université Catholique de Louvain, Brussels, Belgium

$D$ Baeten is a senior clinical investigator of the Fund for Scientific Research (FWO)-Vlaanderen.

\section{REFERENCES}

1 Veys EM, De Keyser F. Rheumatoid nodules: differential diagnosis and immunohistological findings. Ann Rheum Dis 1993;52:625-6.

2 Edwards JCW, Wilkinson LS, Pitsillides AA. Palisading cells of rheumatoid nodules: comparison with synovial intimal cells. Ann Rheum Dis 1993; 52:801-5.

3 Kerstens PJ, Boerbooms AM, Jeurissen ME, Fast JH, Assmann KJ, van de Putte LB. Accelerated nodulosis during low dose MTX therapy for rheumatoid arthritis: an analysis of ten cases. J Rheumatol 1992;19:867-71.

4 Kaiser MJ, Bozonnat MC, Jorgensen C, Daures JP, Sany J. Effect of etanercept on tenosynovitis and nodules in rheumatoid arthritis. Arthritis Rheum 2002;46:559-60.

5 Cunnane G, Warnock M, Fye KH, Daikh DI. Accelerated nodulosis and vacsulitis following etanercept therapy for rheumatoid arthritis. Arthritis Rheum 2002;47:445-9.

6 Kekow J, Welte T, Kellner U, Pap T. Development of rheumatoid nodules during anti-tumor necrosis factor alpha therapy with etanercept. Arthritis Rheum 2002;46:843-4.

7 Baeten D, Kruithof E, Van Den Bosch F, Demetter P, Van Damme N, Cuvelier $\mathrm{C}$, et al. Immunomodulatory effects of anti-TNF- $\alpha$ therapy on synovium in spondyloarthropathy: histologic findings in eight patients from an open-label pilot study. Arthritis Rheum 2001;44:186-95.

8 Elewaut D, de Keyser F, De Wever N, Baeten D, van Damme N, Verbruggen $G$, et al. A comparative phenotypical analysis of rheumatoid nodules and rheumatoid synovium with special reference to adhesion molecules and activation markers. Ann Rheum Dis 1998;57:480-6.

9 Wikaningrum R, Highton J, Parker A, Coleman M, Hessian PA, RobertsThomson PJ, et al. Pathogenic mechanisms in the rheumatoid nodule: comparison of proinflammatory cytokine production and cell adhesion molecule expression in rheumatoid nodules and synovial membranes from the same patients. Arthritis Rheum 1998:41:1783-97.

10 Tak PP, Taylor PC, Breedveld FC, Smeets TJM, Daha ME, Kluin PM, et al. Decrease in cellularity and expression of adhesion molecules by anti-tumor necrosis factor $\alpha$ monocloncal antibody treatment in patients with rheumatoid arthritis. Arthritis Rheum 1996;39:1077-81.

11 Keane J, Gershon S, Wise RP, Mirabile-Levens E, Kasznica J, Schwieterman WD, et al. Tuberculosis associated with infliximab, a tumor necrosis factor alpha-neutralizing agent. N Engl J Med 2001;345:1098-104.

12 Merrill JT, Shen C, Schreibman D, Coffey D, Zakharenko O, Fisher R, et al. Adenosine Al receptor promotion of multinucleated giant cell formation by human monocytes: a mechanism for methotrexate-induced nodulosis in rheumatoid arthritis. Arthritis Rheum 1997:40:1308-15.

13 Edwards JCW, Cambridge G. Rheumatoid arthritis: the predictable effect of small immune complexes in which antibody is also antigen. $\mathrm{Br} J$ Rheumatol 1998;37:126-30.

14 Edwards JCW, Blades S, Cambridge G. Restricted expression of Fc $\gamma$ RIII $(C D 16)$ in synovium and dermis: implications for tissue targeting in rheumatoid arthritis. Clin Exp Immunol 1997; 108:401-6.

15 Morgan AW, Griffiths B, Ponchel F, Montague BMN, Ali M, Gardner PP, et al. $\mathrm{Fc} \gamma$ receptor type IIIA is associated with rheumatoid arthritis in two distinct ethnic groups. Arthritis Rheum 2000;23:28-34. 